\title{
Circulating Environmental Logistics Channel for Sustainable Society
}

\author{
Hisao Fujimoto \\ Osaka University of Economics, Osaka, Japn
}

\begin{abstract}
This paper suggests the important role of trust as a governance mechanism for the circulating environmental logistics channel for reuse and recycle. Three types of the circulating logistics channels are discussed. The first is the recycle channel, where an actor (a firm) can govern total channel and its flow. In this channel, an actor bears the role of entrance and exit, and processes goods, resources, and waste. It may be called as the closed circulating logistics channel. The second is the recycle channel of kitchen garbage, which is governed by plural actors, such as firms, consumers, and governments, based on trust. This channel may be called as the open circulating logistics channel. The third is the recycle channel with intermediate traders and retailers. This channel may be called as the intermediate circulating logistics channel. It suggests to us that actors with autonomy and volunteerism can promote and make a successful circulating environmental logistic channel under the mutual trust and the cooperative role sharing.
\end{abstract}

Keywords: circulating environmental logistics channel, sustainable society, governance mechanism, mutual trust, role sharing

\section{Introduction}

It has been becoming a serious social and economic issue that the enormous abandonment of products, materials, and wastes from the mass production and consumption has been bringing the destruction and contamination of the earth environment. The recycling and reuse of these enormous wastes can economize the social useful resources. It can also solve the problems of facility shortages and the increasing cost for processing wastes. Among many countries, this environmental issue has been crucial along with economic and social development under limited resources.

For supporting and promoting the recycle and reuse of wastes and materials, the conventional distribution channel concept, which only considers the one-way process from production to consumption, is not sufficient. There needs to consider the backward or reverse channel which includes the collecting and recycling process of resources and wastes after consumption. Moreover, it is important that two types of channels are not only recognized respectively, but that they are combined up effectively. If this combined channel is called as circulating environmental logistics channel, it has some different features from the conventional channel.

The new circulating logistics channel (CLC after this) will include various members and need the long-range perspective for the efficient and effective operation. It will also need the governance mechanism for inter-organizational factors.

Hisao Fujimoto, MBA, Professor, Department of Information Technology and Social Sciences, Osaka University of Economics, Osaka, Japan. 
This paper explores the importance of trust as the governance mechanism and fundamental features of CLC from the several examples in Japan.

\section{Basic Policy for Recycling-Based Society}

In Japan, "Basic Law for Establishing the Recycling-Based Society" has been enacted in 2000. At in same period, "Container and Packaging Recycle Law" (2000), "Law on Promoting Green Purchasing" (2001), "Law for Promotion of Effective Utilization of Resources" called "Recycle Law" in general (2001), "Electric Household Appliance Recycling Law" (2001), "Food Recycling Law" (2001), "Contraction Recycling Law" (2002), "Waste Management and Public Cleansing Law" (2003), "Automobile Recycling Law" (2005) have been enacted one after another.

In "Container and Packaging Recycle Law", renewing a past idea that only local governments completely account for processing waste of container and packages, it tried to promote recycling under new rules that consumers bear the discretion exhaust, local governments bear the separate collection, and traders bear the re-commercialization of wastes respectively. The re-commercialization of four items of glass containers, pet bottles, plastic containers, and paper containers is obligated. Traders can select one method from three alternatives: (1) voluntary recall route, (2) designated corporation route, (3) original route.

Almost of used discarded home electronic appliances products exhausted in ordinary homes is partly returned as metals after processing of crushing in past. "Electric Household Appliance Recycling Law" obligates retailers to receive discarded home electric appliances, manufacturers to recycle them, and consumers to pay the fee for collection, delivery and recycle for air conditioner, TV, refrigerator, and washing machine. It also obligates manufacturers to clear the recycle level of $50-60 \%$ and collect fluorocarbon. To secure the appropriate delivery of the specific home electric appliances from consumers to retailers and manufacturers, the manifesto system is settled.

In "Food Recycling Law", a large amount of food wastes an unsold stuff and half-eaten is brought in the process of manufacturing, distribution, and consumption. Whereas these food wastes occupy around $30 \%$ of municipal wastes, the recycling ratio is still around $10 \%$.

The basic idea in the master plan for Establishing the Recycling-Based Society suggested that this society can be attained only by the role allotment and cooperation of stakeholders. However, the attainment of effective recycling is still not sufficient.

Not limiting to Japan, the management of the recycling flow of such resources is becoming an indispensable part in the corporate strategy in a lot of worldwide global businesses. The main following factors exist in its background.

At first, business enterprises must be concerned with the consideration and responsibility of environmental issues. Business companies cannot disregard the public concern with companies' environmental friendliness for their continued development any longer. The public concern with the environmental issues becomes a pressure that it is necessary for companies to consider the environmental issues. In addition, as people can access to various on environmental issues using the Internet and SNS, enthusiastic people' concerns and behaviors become more important for companies. Moreover, these people demand the positive result for companies by settling on and executing construction of the management system and circulate logistics channel that can achieve the recovery of resources after abandonment. Companies positively working on such environmental 
issues and maintaining the environmental compliance will produce the image as "Green Company" and "Environment Friendly Company", which are crucial for their business strategy.

Second, the law and policy concerning the recycling of products and resources come to be executed. Several laws have been reacted in some countries of Europe in 1990s. For instance, the collection of packages of all packaged commodities has been imposed on companies by "Packaging Ordinance Act" in Germany. In addition, "German Recycling and Waste Control Act" requests for manufacturing companies to work on the technique and technology to promote the reduction of wastes and the collection of inevitable wastes positively.

The Commission of European Communities adopted the request for the promotion of recycling, the reduction of hazardous articles, and the appropriate abandonment of wastes of electric and electronic appliances in1998.

As mentioned above, also in Japan, various laws and ordinances are enforced under "Basic Law for Establishing the Recycling-Based Society". These laws and ordinances by such a national local authority have a great influence on companies concerned with environmental issues in their corporate strategy. To improve their environmental performance, companies must advance the environmental tie-up and green alliances with related companies and consumers in logistics channel.

Lastly, not only important the reduction of the abandonment and the processing cost of wastes, collecting resources for recycling and its re-use can produce the profits for companies. For instance, Xerox has reported the savings of 3.5 million dollars per year in Europe by reverse logistics activities (Maslennikova \& Foley, 2000). Same cases also have been reported in several industries such as auto parts, computers, and airline products (Ayres, Ferrer, \& Leynseele, 1997). Therefore it is clear that a holistic aspect concerning the logistics channels including both forward and backward channels will be necessary.

For Japan having been behind in advanced European countries in environmental issues, it has been planning 10 years in 1990s and 21th century will be the execution period for working on environmental issues. For working on environmental issues effectively, we need to consider the framework of CLC and governance mechanism in CLC.

\section{Framework of CLC}

After reviewing many literatures, Carter and Ellram (1998) concluded that most of literatures was descriptive and exploratory, and examined only relatively narrow aspect of reverse logistics, such as recycling. They also examined the internal and external constraints and drivers as critical factors in the reverse logistics process (also see Carter \& Carter, 1998). The reverse logistics is also attracting attentions from the business strategy. Tibben-Lembke (1998) approached from the viewpoint of the total cost of ownership. Blumberg (1999), Inman (1999), Mayer (1999), and Schwartz (2000) stress that the managing, handling, and disposition of materials and returned goods can bring business opportunities and/or strengthen the market position. According to Caldwell (1999), not only in the conventional commodity flow channel, the reverse logistics is becoming the important part of the business in the online sales and direct marketing of digital contents like as music CD. The free return strategy and the environmental concerned disposal of materials can increase the customer satisfaction (DiMaggio, 2000).

Zikmund and Stanton (1971) is the first consideration of the distribution of wastes on the concept of the backward channel (BWC). They defined BWC as the return channel of reusable packages and materials from consumer to producer. They finally pointed out the four concrete forms of return channel as: (1) direct 
backward channel, (2) backward channel with a atypical intermediary, (3) backward channel with traditional middlemen, (4) indirect backward channel using trash-collection specialists.

Fuller, Allen, and Glaser (1996) describe a typology of reverse channel networks as the following: (1) corporate-integrated networks, (2) waste hauler-public recovery networks, (3) specialized reverse dealer-processor networks, (4) traditional "forward" wholesaler-retailer networks, and (5) temporary-facilitator networks. They also suggest the concepts of the closed-loop and open-loop application.

There is an only difference from the conventional forward channel (FWC) in that the typical consumer does not emulate the proactive role of the commercial channel member in spite of his role to sell and distribute waste materials to the market (see Fuller et al., 1996). From the antecedent researches, several features of BWC and CLC can be pointed out.

First, consumers are not only a consuming actor, but also the producer of resources after consuming and the promoter of its recycling. Whereas consumers have not been considered as the proactive member in FWC, they are considered as the proactive members in BWC and CLC. Consumers are expected to be aggressive participants in BWC and CLC. Their judgements and behaviors will determine whether wastes will be the useless garbage or the recyclable and re-useful resources.

Second, BWC and CLC will include public organizations, such as national and local governments and various non-profit organizations. Third, BWC and CLC are not for the narrow profit of specific organization. They are operated for the sustainable economic and social development of our ecosystem.

Last, the channel consisted of such a constituent needs to have the governance mechanism, which function based on not the conventional authority nor the market-price mechanism, but the long-range trust.

In this paper, three types of the circulated logistics channels are discussed. The first is the recycle channel, where an actor (a firm) can govern total channel and its flow. In this channel, an actor bears the role of entrance and exit, and processes goods, resources, and wastes. It can be called as the closed CLC. The second is the recycle channel of kitchen garbage, which is governed by plural actors, such as firms, consumers, and governments, based on trust. This channel can be called as the open CLC. The third is poisoned between closed CLC and open CLC. In this logistics channel, actors are restricted, and middlemen and/or intermediate special traders perform an important role. This channel can be called as the intermediate CLC.

\section{Typology of Governance Mechanism}

After the Williamson's transaction cost economics, the third mechanism has been recognized between markets and hierarchies. Arndt (1981) described three types of economic control systems as markets, politics, and hierarchies, and coordinating mechanism as price, bargaining, and direct assignment (command). Powell (1991) suggested three systems as markets, networks, and hierarchies, and methods of resolution as price, reciprocity, and administrative fiat. In Bradach and Eccles (1991), coordinating mechanisms are described as price, trust, and authority. Whereas these three coordinating mechanism seem to be independent and mutually exclusive, they can be related each other in various ways as pointed out. For example, the price mechanism can only be operated with trust for prices, products, and behaviors of members. Among of three coordinating mechanisms, trust occupies the important position especially in the open network. Whether it is operated in success or not is depend on the degree of trusts of network members. The importance role of trust as a governance mechanism for CLC will be discussed with introducing several cases in next sections. 


\section{Cases of Closed CLC}

In the closed CLC, an actor can control the entrance, process, and exit of goods and materials. In the convenience store in Japan, unsold lunch baskets and daily dishes are collected and processed into manure or feed. Vegetables and meats, which are produced using these manure and feed, become raw materials of lunches and daily dishes again. In this recycling system, a convenience store and/or its group operates the circulation of production, distribution, selling, abandonment, and reuse. It can avoid the difficulty of collection, sorting, assortment and disposition from the aspect of health administration. The other example is CLC for disposal cameras. Consumers bring their finished disposal cameras to the Development-Printing-Enlargement (DPE) stores for development. Manufacturers of disposal cameras can certainly collect finished disposal cameras through DPE stores. These two cases are relatively successful, because wastes and materials are restricted and members of CLC are strongly tied up.

Another example is the closed CLC based on "Specific Home Electronics Re-commercialization Law", the so-called "Home Electronics Recycling Law", which has been enforced since April 2001 in Japan. This law has imposed a duty of recycling of main four items of home electronics, air-conditioner, television, washing machine, and refrigerator, to the manufacturer or importer. It is based on the consideration that those who have the specialized knowledge about the contents of products can accomplish the recycling properly and efficiently. The fact that about $80 \%$ of retailers already had been taking over used home electronics at the time of consumer's replacement could act to impose retailers to collect and convey used home electronics. Consumers, on the other hand, are responsible to use their home electronics longer for restraining product abandonment, hand over their used home electronics to proper retailers, and respond to a claim for payment of predetermined charge required for recycling.

The last CLC has several different characteristics from the former two CLC. First, consumers have to bear costs for recycling used home electronics, which used to be collected by local government or specialized dealer-processor without costs for consumers. It means that manufacturer and retailer can claim a payment for consumers to abandon their home electronics. It can bring the consumers' illegal abandonment and the increasing monitoring cost for local government. It is depending on the moral and self-consciousness of consumers. Second, there is the problem that products from the recycled materials can obtain sufficient demands and markets in the competition with products from new virgin materials. It cannot be denied that recycled products tend to be in the disadvantage position in price and quality compared to new products. Third, the last CLC is difficult to be controlled by one actor. Manufacturers and retailers will not cooperate without economic incentives, such as reservation of the technical innovation and competitive advantage by recycling activities. Consumers will have no tangible profit. They only have the psychological factor of duty and solidarity. Whereas the local government can enforce its mandatory control power, there is a limit for its effective enforcement.

\section{Cases of Open CLC}

Wastes and materials, which cannot be circulated in the closed CLC, have to be disposed by the local government. While most of wastes have been disposed as the incineration and/or reclamation disposal, the open CLC is a trial for recycling reusable wastes. In the open CLC, manufacturers and retailers have no strong commitments. Local government also has no strong enforcement based on the institutional law. Consumers 
have no economic incentives and legitimate duty to cooperate with the open CLC. In this situation, trust seems to be important role for the open CLC. Price, which has its base on economic incentives, and command, which has its base on authority and legitimacy, cannot be expected to be an effective governance mechanism for the open CLC. Trust can support other two mechanisms in their base and operate the open CLC effectively. For exploring it, the recycling of kitchen garbage in Asakura town in Fukuoka is discussed.

Asakura town has the population of 10,690 and the 2,680 families. To construct and maintain the circulated channel of kitchen garbage, Asakura High-speed Compost Processing Center (AHCP Center) has been operating for collecting, processing, and reducing kitchen garbage since 1983. It has been considered as tender for the earth environment that kitchen garbage can be recycled as compost not to be incinerated and reclaimed. Figure 1 depicts the brief process of CLC in Asakura town.

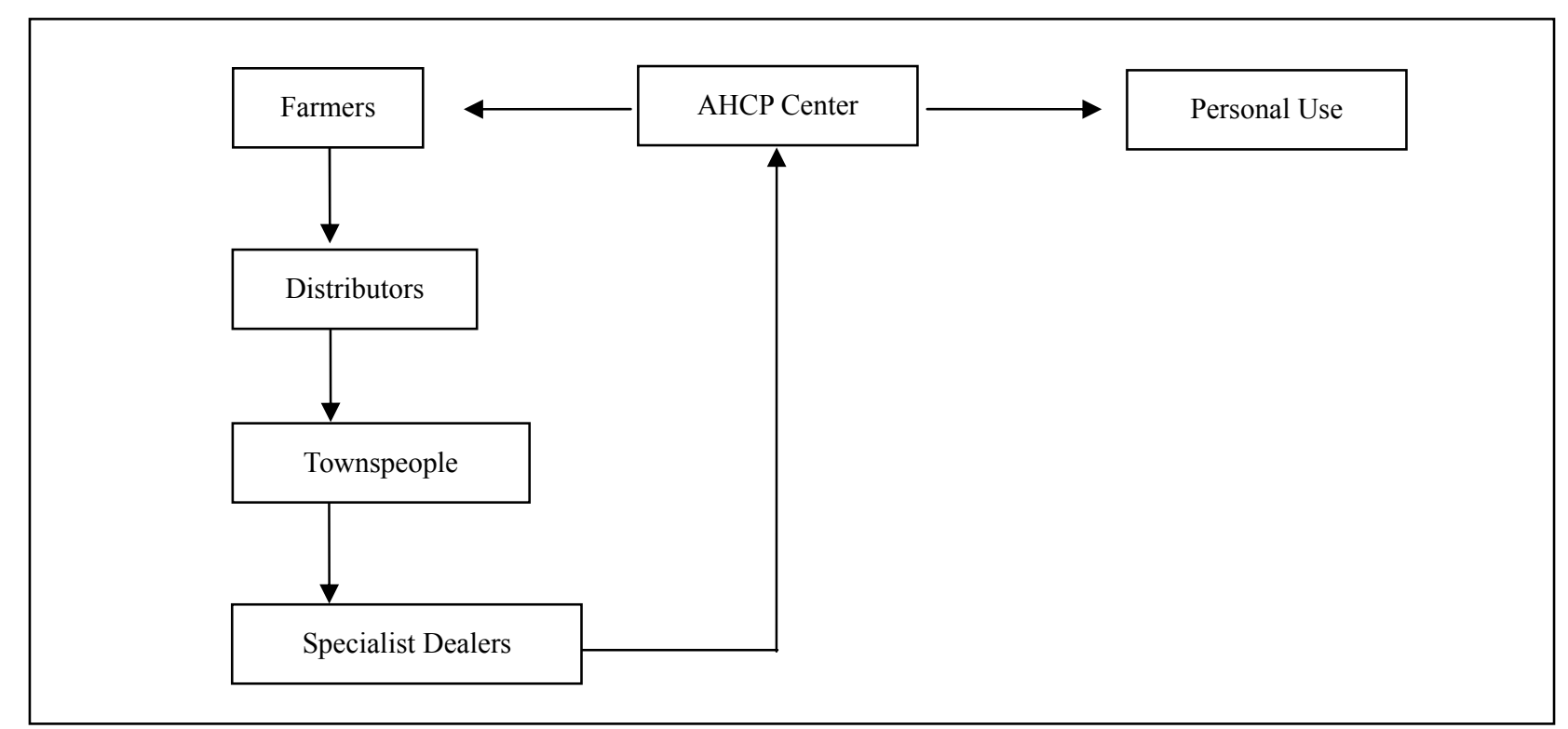

Figure 1. CLC of kitchen garbage in Asakura town.

Vegetables and fruits, which are produced by farmers flow in the FWC to townspeople. After consumption, wastes as kitchen garbage is collected by specialist dealers, and carried to AHCP Center. AHCP Center processes kitchen garbage to compost for around one month without smoke and sewage. Compost from this CLC is marketed at 150 Yen per $8 \mathrm{Kg}$ for farmers and personal uses of townspeople.

A half of families co-operated the collection of kitchen garbage in 1999. Taking account that a half of families in this area are farmers, residents are highly cooperative with this local CLC. Townspeople are considered to have cooperated based on the joint consciousness to the environment, in spite that they have to go to a local government office to take purposely the bag into which kitchen garbage is put, and have to classify kitchen garbage and other garbage. Farmers as producer also have no responsibility for recycling and using resulted compost.

The other substantial problem is the gap of supply and demand for compost. Whereas kitchen garbage and compost produced from it are annually constant, demand for compost is seasonally inclined. As demand for personal use increases, farmers become difficult to get their necessary compost. It needs the collection of kitchen garbage from outside of Asakura town for increasing production of compost to the necessary amount. It will prevent the successful recycling system in Asakura town. 
Based on the annual maintenance and administrative expenses of AHPC Center and considering expenses and sales amount, AHCP Center is in the red economically. It comes from the high processing cost. The processing cost of recycling kitchen garbage is estimated 50,000 Yen per ton, while the cost for incinerating kitchen garbage is several hundred Yen per ton. The cost for rebuilding the existing center is also hitting hard on the local government budget. Asakura town is faced with a decision whether participating in the enlarged recycling project with neighbor areas or keeping on the independent recycling system.

For farmers, the use of compost from the recycling system has several problems. They have to use a lot of compost, which has no immediate effect compared with a chemical fertilizer, with hard work and special knowledge though they know the use of compost is better for lands and the earth environment. Compost is also restricted in its usage.

Unfortunately, because of the high costs and conflicts with next towns, AHCP Center and the recycle system had been closed in 2002. It means that the successful system of recycling in the large regional network is difficult without the mutual understanding of its importance. There needs the change of consciousness for consumers and the promotional effort of the local government. They are suppliers of kitchen garbage and also purchasers of farm products produced from the recycling compost. Consumers have to be the ecological and green consumer without avoiding the share of environmental expenses.

\section{Cases of Intermediate CLC}

The intermediate CLC emphasizes the important roles of intermediaries. In this channel, wastes will be returned on the re-use base. However, wastes is only returned as it is different from the open CLC where wastes is returned as materials or resources for the reproduction. It is because intermediaries are positioned the next of consumers and have the important role in this channel. This intermediate CLC has other difference from open CLC. Whereas costs derivative from return channel are covered by the public subsidy and/or finance because of the insufficient markets for this channel, costs can be covered by intermediaries in the intermediate CLC. In this sense, the intermediate CLC may be considered as an amalgamation of market and non-market system.

The Shiromi Shopping Street in Kumamoto city is the case of the intermediate CLC. The ecological action of Shiromi has been activated from 1999 with the corporate identity (CI) of "the eco-station shopping street". In 2000, Shiromi made its original certificate of KSO14001. The purpose of this certificate is as follows.

(1) Formation of the eco-shopping street

(2) Environment education and learning

(3) Formation of local community

The development of Shiromi has three aspects. The first aspect is the internal network for the collaboration of component members. This internal network has a role of integrating members on the concept or slogan of "the environmental shopping street". The key for success is that this integral concept can be agreed and shared by members with its fun and profitability. Without them, members and its organization cannot be operated. In this sense, the internal network needs the price/market governance mechanism. It can be a system of economy and ecology.

The second aspect is the community network taking in consumers and townspeople and getting their collaboration. This collaboration can be supported by their voluntary consciousness and solidarity. The functioning of Shiromi as a eco-station is based on the loose network with the reciprocity and trust. However, 
this loose network based on reciprocity and trust has no coercion power and economic incentives. It will need a rule as a control mechanism and an economic incentive mechanism.

The third and last aspect is the external network including local government, collection and recycling dealers, and manufacturers. Dealers and manufacturers will participate and act as economic concern. This part of network consists of economic network on the price/market mechanism. The other part of network consisting from political network subsuming local government will basically depend on reciprocity/trust and authority.

\section{Concluding Remarks}

The discussion of cases with the framework of the closed and open CLC can suggest us to consider and explore the importance and problems of CLC.

First, although the locus of responsibility is clear in the closed CLC, it is not clear in the open CLC and the intermediate CLC. In the case of open CLC in Asakura town, famers, townspeople, and local government have their roles respectively. However, there is no clear responsibility for the recycling kitchen garbage and compost. Whereas the local government has the responsibility to operate the recycling system and bear most costs of the system, the enforcement power of local government is weak, and the successful operation of the open and unstable CLC depends on voluntary wills and trust and cooperation of participants. In the intermediate CLC, there lies the basic price/market mechanism which is controlled by the reciprocity/trust mechanism.

In conventional FWC and closed CLC, firms and public governments have been controlling channels with coordination mechanisms as price and/or authority as proactive actor. In contrast, consumers will be expected as proactive actor to participate in and operate CLC. Coordinating mechanisms of price and authority cannot be denied and excluded as CLC includes economic activities of participants. However, it is also clear that CLC cannot be successfully operated only with price and authority. Cases may suggest the importance of trust for operating CLC and combining markets and hierarchies as the economic and social embedded bond. Actors with autonomy and volunteerism can operate environmental logistics channel based on mutual trust cooperation. Their action can be supported by their behavior principles which are backed up with the psychological factors and their propensity for role sharing.

\section{References}

Arndt, J. (1981). The political economy of marketing systems: Reviving the institutional approach. Journal of Macromarketing, $1(2), 36-47$.

Ayres, R., Ferrer, G., \& Leynseele, T. V. (1997). Eco-efficiency, asset recovery and remanufacturing, European Management Journal, 15(2), 557-574.

Blumberg, D. F. (1999). Strategic examination of reverse logistics \& repair service requirements, needs, market size, and opportunities. Journal of Business Logistics, 20(2), 141-159.

Bradach, J. L., \& Eccles, R. G. (1991). Price, authority and trust: From ideal types to plural forms. In G. Thompson, F. R. Levacic, and J. Mitchell (Eds.), Markets, hierarchies and networks: The coordination of social life (pp. 277-292). Thousand Oaks, California: Sage Publications.

Caldwell, B. (1999). Reverse logistics. Information week, 729, 48-56.

Carter, C. R., \& Carter, J. R. (1998). Interorganizational determinants of environmental purchasing: Initial evidence from consumer products industries. Decision Science, 29(3), 659-684.

Carter, C. R., \& Ellram, L. M. (1998). Reverse logistics: A review of the literature and framework for future investigation. Journal of Business Logistics, 19(1), 85-102.

Dimaggio, J. (2000). Reverse psychology. Warehousing Management, 7(4), 30-32. 
Fuller, D., Allen, J., \& Glaser, M. (1996). Materials recycling and reverse channel networks: The public policy challenge. Journal of Macromarketing, 16(1), 52-72.

Inman, R. A. (1999). Environmental management: New challenges for production and inventory managers. Production and Inventory Management Journal, 40(3), 46-49.

Maslennikova, I., \& Foley, D. (2000). Xerox’s approach to sustainability. Interface, 30(3), 226-233.

Mayer, H. (1999). Many happy returns. Journal of Business Strategy, 20(4), 27-31.

Polanyi, K. (2001) The great transformation: The political and economic origins of our time (2nd ed.). Boston: Beacon Press.

Powell, W. W. (1991). Neither market nor hierarchy: Network forms of organization. In G. Thompson, F. R. Levacic, and J. Mitchell (Eds.), Markets, hierarchies and networks: The coordination of social life (pp. 265-276). Thousand Oaks, California: Sage Publications.

Schwartz, B. (2000). Reverse logistics strengthens supply chains. Transportation \& Distribution, 41(5), 95-100.

Tibben-Lembke, R. S. (1998). The impact of reverse logistics on the total cost of ownership. Journal of Marketing Theory and Practice, 6(4), 51-60.

Zikmund, W. G., \& Stanton, W. J. (1971). Recycling solid wastes: A channels of distribution problem. Journal of Marketing, 35(3), 34-39. 